\title{
El Aprendizaje del Violín en Alumnado con Discapacidad Auditiva
}

\section{Violin Learning in Hearing Impaired Students}

\author{
(iD) Luis Sánchez Sánchez \\ Consejería de Educación de la Comunidad Valenciana, España \\ sanchez_luisana@gva.es
}

\begin{abstract}
Resumen: Este artículo informa sobre la investigación efectuada para facilitar la enseñanza del violín en alumnado con discapacidad auditiva en las Escuelas y Conservatorios de Música, recogiendo las estrategias y recursos que se han obtenido para favorecer la inclusión de estos estudiantes. Se partió de dos dificultades principales: la dificultad que presenta el aprendizaje de un instrumento musical para el alumnado con discapacidad auditiva, y los problemas específicos que el violín tiene para las personas sordas (HASH, 2003). La metodología de esta investigación ha sido la etnografía, orientada hacia una educación reflexiva y trabajo colaborativo a través del diálogo de saberes, gracias al contacto con profesionales vinculados a esta área y con este alumnado. Los resultados concretan propuestas didácticas para propiciar una educación inclusiva musical para el alumnado de violín con deficiencia auditiva. Finalmente, el trabajo visibiliza prácticas inclusivas en este ámbito musical, confirmando que no es necesario un repertorio o método diferente para estos estudiantes, sino básicamente adaptaciones a nivel metodológico y didáctico.
\end{abstract}

Palabras clave: Música y musicología. Educación especial. Pedagogía. Etnografía y etnología. Metodología.

Abstract: This article reports on the research carried out to facilitate the teaching of the violin in students with hearing disabilities in the Music Schools and Conservatories, gathering the strategies and resources that have been obtained to favor the inclusion of these students. Two 
main difficulties started: the difficulty of learning a musical instrument for students with hearing disabilities, and the specific problems that the violin has for deaf people (HASH, 2003). The methodology of this research has been ethnography, oriented towards reflective education and collaborative work through the dialogue of knowledge, thanks to contact with professionals related to this area and with this student body. The results specify didactic proposals to promote an inclusive musical education for violin students with hearing impairment. Finally, the work makes visible inclusive practices in this musical field, confirming that a different repertoire or method is not necessary for these students, but basically adaptations at a methodological and didactic level.

Keywords: Music and musicology. Special education. Pedagogy. Ethnography and ethnology. Methodology.

Submetido em: 21 de fevereiro de 2021

Aceito em: 5 de setembro de 2021 


\section{Introducción}

La diversidad es una realidad y está presente en los centros de enseñanza: "La diversidad en la realidad de un aula, es algo ya admitido y aceptado como referencia básica para proporcionar a todos los alumnos aquella educación adecuada a sus características y posibilidades", afirman Bernal y Gaytán (2011: 53). Los conservatorios de música no son ajenos a esta circunstancia y, de hecho, hay Conservatorios y Escuelas de Música que incluyen en su alumnado a niños y personas con diferentes grados de discapacidad (SABBATELLA, 2004: 135).

Por ello, esta investigación ha tenido como objetivo básico clarificar las dudas que pueden tener los docentes de violín sobre cómo enseñar al alumnado que presenta discapacidad auditiva, concretando recursos y estrategias que contribuyan en este cometido. Todo desde el convencimiento que, "en el aprendizaje, como en cualquier otra actividad o situación, se pueden franquear barreras", como afirma Quintero (2000: 32). Y que también hay diversos caminos y formas para aprender: "es indiscutible que todos somos diferentes y aprendemos de manera diferente", según Cabero y Córdoba (2009: 64). En definitiva, garantizar la importancia de cada estudiante, sin duda, el desafío más transcendental de todos los métodos (AINSCOW, 2008: 276).

A nivel educativo, la educación del alumnado sordo ha despertado interés como demuestra la realización de 19 Congresos Internacionales de Educadores de Sordos desde 1878 hasta el año 2000 en diferentes países de América, Asia y Europa ( $\mathrm{NOCl}$, 2004: 320). Además, la evolución histórica es manifiesta, pues "se ha pasado de considerar a la sordera como una deficiencia a considerarla como una diferencia", como afirman Torres, Rodríguez, Santana y González (1995: 11). En España, a partir de 1960 y hasta la actualidad, se ha producido un impulso en los avances de la educación del alumnado sordo, igualándose al resto de países occidentales (NOCl, 2004: 319). 
Para la educación del alumnado con discapacidad auditiva existen varias tendencias pedagógicas por parte de los distintos métodos de comunicación (RIVERO, ZAMORA Y PADRÓ, 2008). Si el alumnado dispone de resto auditivo suficiente, suele utilizarse el lenguaje oral junto con ayudas técnicas (audífonos, implante coclear, sistemas de frecuencia modulada, etc.), además de apoyo pedagógico y logopédico. En caso de sordera profunda, suele emplearse la vía visual como medio de comunicación a través de sistemas bimodales, lectura labial, lengua de signos, etc. Ambos métodos, tanto la lengua oral como la lengua de señas no suponen una oposición y pueden complementarse y ser eficientes (SKLIAR, 1997: 28).

Precisamente, en el ámbito académico, una problemática es el desconocimiento de la lengua de signos por parte de los docentes (SKLIAR, 1997: 29). En España, la formación en Lengua de Signos Española (LSE) se ha incrementado en los últimos años, pero probablemente aún tiene margen de mejora, pues en otros países como Suecia, la lengua de signos es muy respetada y se enseña en algunas escuelas de oyentes (SVARTHOLM, 2003).

En el ámbito social se han producido grandes avances, a nivel de reconocimiento legal de los derechos de las personas sordas (en inclusión escolar, en disponer intérpretes en los marcos educativos, legales y administrativos, en elección de modalidad comunicativa, etc.) y al reconocimiento de la lengua de signos como lengua natural de los sordos (TORRES et al., 1995: 11). Precisamente, en relación a los lenguajes de señas, herramienta indispensable de comunicación para la población con sordera profunda, posee más de 60 millones de usuarios a nivel mundial, teniendo cada país su propia lengua de signos y denominación particular (RIVERO et al., 2008).

En el ámbito cultural, el estudio de Darrow (1993: 105) mostró que la música tiene importancia en la cultura de las personas sordas, aunque es considerablemente más limitada que en la de las personas oyentes. Prestigiosos músicos de la historia de la música como los compositores Ludwig Van Beethoven, 
Gabriel Fauré o Bedrich Smetana, perdieron a lo largo de los años su audición (TRANCHEFORT, 1989). En la actualidad encontramos también diversos músicos importantes con esta deficiencia como la percusionista Evelyn Glennie, que a pesar de su sordera profunda es una solista muy reconocida (HASH, 2003). Y cada vez existen más discapacitados auditivos con interés por la música y la interpretación musical (PEÑALBA, MORIYÓN, LUQUE Y CABEZAS, 2017: 87).

Entrando en la educación musical de alumnado con discapacidad auditiva, las limitaciones son evidentes y dependen del resto auditivo que tenga el estudiante, pero incluso en sorderas profundas se puede aprovechar la sensibilidad a las frecuencias bajas para trabajar secuencias rítmicas que propician el desarrollo de la melodía y la entonación por medio de juegos corporales (GARCÍA Y HERRERO, 2008: 37). De igual parecer es Otero (2015, p.134), que expone que la sordera no es un impedimento para percibir la música, pues ésta va más allá de las sensaciones que percibe el oído.

Hay trabajos sobre la enseñanza instrumental de los sordos en el panorama internacional (HASH, 2003) clarificando las posibles dudas en el profesorado, o en España (MONTOYA, 2014) enfocado a la flauta dulce y (MOSTEYRíN, 2009) que aborda la técnica de la tacto audición, para que el músico sordo perciba las sensaciones vibrátiles. También son destacables las aportaciones de las nuevas tecnologías en esta área como muestra el trabajo de Hiraga y Kawashima (2006) en Japón que expone un método para enseñar música a personas con problemas de audición a través del ordenador y aplicaciones informáticas, demostrando la eficacia de la ayuda y asistencia visual de estos recursos tecnológicos, o el sistema de aprendizaje asistido por computadora (CAMLS) de Yang, Lay, Liou, Tsao y Lin (2007) para ayudar a comprender al estudiante con discapacidad auditiva qué son el tono y el tempo para posteriormente aprender a tocar canciones. Igualmente es reseñable la investigación de Nanayakkara, Wyse, Ong y Taylor (2013) que aporta recursos para el acercamiento a la música de 
El Aprendizaje del Violín en Alumnado con Discapacidad Auditiva Luis Sánchez Sánchez

las personas con discapacidad auditiva, en este caso la silla háptica vibrante y una pantalla con efectos visuales informativos.

En el ámbito pedagógico-orquestal, encontramos en España la iniciativa de la Jove Orquestra Graeme Clark (JOGC) ${ }^{1}$, dirigida por Jordi Cos y compuesta por diez jóvenes músicos entre 9 y 18 años (figura 1), todos ellos sordos con implante coclear y que compaginan la actividad en esta orquesta con sus estudios en las Escuelas de Música de sus localidades (T. Vargas, entrevista, 14-05-2020).

Figura 1 - Jove Orchestra Graeme Clark (JOGC)

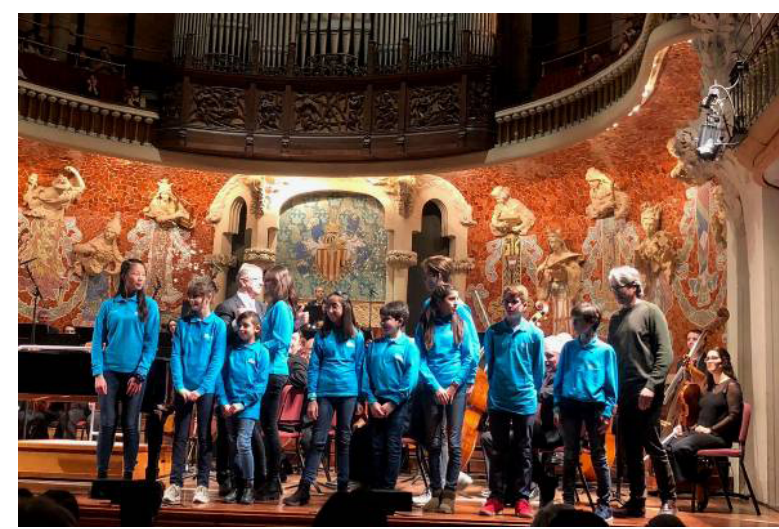

Fuente: fotografía facilitada por el Sr. Vargas

Descripción de la imagen: concierto de la Orquesta Sinfónica del Vallés en el Palau de la Música Catalana, en el que interpretó una pieza compuesta por los componentes de la JOGC (febrero de 2020).

En el ámbito de las bandas de música, hay también casos como el del director de banda sordo Fred Fancher, que dirigió una banda militar para formación de sordos entre 1923 y 1942 en la Escuela de Sordos de Illinois (HASH, 2003).

Y es que, si bien está demostrado que los estudiantes con discapacidad auditiva pueden convertirse en buenos músicos, algunos profesores de instrumento son reticentes a su enseñanza debido a algunas inquietudes (HASH, 2003), como puede ser la falta de familiaridad con las capacidades de los estudiantes sordos

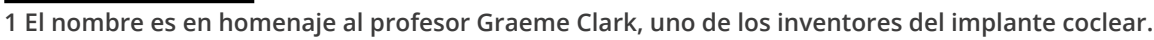


o el temor de que estos músicos afecten negativamente la calidad del rendimiento.

Con este panorama, la investigación concretó estas preguntas de investigación: ¿Puede aportarse alguna herramienta que potencie la inclusión de este alumnado en el aula de violín? ¿Es preciso un programa o repertorio específico para la atención de estos estudiantes con discapacidad auditiva?

Estas preguntas de investigación tenían en cuenta dos dificultades:

- El obstáculo que presenta para el aprendizaje de un instrumento musical no disponer con plenas facultades del oído, que es una referencia crucial para la formación musical, ya que la audición es básica en el aprendizaje de la música (WUYTACK Y BOAL, 2009: 43), y precisamente está presente en todos los elementos (melódico, rítmico, formal, tímbrico) que se trabajan en el aula (LÓPEZ DE ARENOSA, 2004: 121).

- Las dificultades específicas que presenta el estudio del violín, hecho demostrado en el mundo de la música para cualquier estudiante (HOPPENOT, 2000: 171). Según Menuhin (1987: 13), entre los obstáculos principales que presenta está que no tiene soporte fijo, el control que requiere en todos los detalles, las manos se utilizan alrededor o por encima del hombro y deben ser muy elásticas, flexibles y fuertes, y la precisión, exactitud y rápido ajuste que precisa la afinación. Esto último, de especial relevancia y dificultad para el alumnado con deficiencia auditiva, al no tener plenas facultades con este sentido. De hecho, instrumentos como el violín o el violonchelo pueden ser demasiado difíciles para los estudiantes con discapacidad auditiva (HASH, 2003), en contraposición con otros instrumentos de cuerda como el bajo eléctrico, la guitarra o el arpa, que permiten sentir las vibraciones de las cuerdas y, éstas, están más cerca del oído. 


\section{Objetivos}

La investigación se centró en ofrecer respuestas a estos problemas y preguntas de investigación, teniendo como objetivo básico facilitar la enseñanza de violín del alumnado con discapacidad auditiva en las Escuelas y Conservatorios de Música, concretando estrategias y recursos que faciliten su formación.

Para lograr este objetivo principal, se han seguido estos cuatro pasos:

- Recopilar información sobre la discapacidad auditiva, los materiales y sistemas de comunicación que emplean las personas sordas, así como los recursos y estrategias que se utilizan en la enseñanza escolar con deficientes auditivos.

- Investigar sobre las dificultades y necesidades que tiene este alumnado y los músicos sordos, y conocer los recursos, proyectos y estrategias que se utilizan en las aulas de música, a través del contacto con Asociaciones, Federaciones y Confederaciones para personas con discapacidad auditiva, agrupaciones musicales que integran sordos, y profesionales que han trabajado con músicos y alumnado de estas características.

- Recoger los resultados, concretando aquellos recursos, estrategias y buenas prácticas oportunas para el alumnado de violín con discapacidad auditiva en los centros de música.

- Analizar las propuestas didácticas planteadas, juzgando si responden a las preguntas y objetivos de la investigación y si ofrecen respuesta a las dificultades que tienen estos estudiantes.

\section{Método}

Todas las cuestiones se abordaron gracias a la etnografía en los escenarios de diversos centros y organismos, así como con 
El Aprendizaje del Violín en Alumnado con Discapacidad Auditiva Luis Sánchez Sánchez

protagonistas de este campo, junto con el conocimiento aportado de las referencias bibliográficas, desde esta triple vertiente:

- Por un lado, se conoció cómo es la enseñanza general de estos estudiantes (la cual compaginan con sus estudios en el centro musical) y se trató de adaptar algunas de esas estrategias a la enseñanza del conservatorio.

- Por otro lado, se han considerado recursos y buenas prácticas de trabajos específicos en esta área (HASH, 2003; MOSTEYRÍN, 2009).

- Por último, se han utilizado manuales de referencia del violín y de su pedagogía (CLAUDIO, 1999; GALAMIAN, 1998; HOPPENOT, 2000; MENUHIN, 1987; PASCUALI Y PRÍNCIPE, 2007), conectando con sus propuestas, que, sin ser específicas para este alumnado con sordera, pueden ser enfocadas para este cometido.

Dada la buena experiencia que la etnografía proporcionó como método de investigación en un área similar de estudio, como era la enseñanza del alumnado de violín con ceguera (SÁNCHEZ, 2017)², se consideró también para esta investigación utilizarla como herramienta metodológica, debido a los resultados positivos que ofrece en escenarios de este tipo, y dirigida especialmente hacia una educación reflexiva y trabajo colaborativo, por medio de un diálogo de saberes (DIETZ, 2003, DIETZ, 2009; DIETZ, 2011; DIETZ, 2012; LARA Y MUÑOZ, 2019; MUÑOZ, 2012; MUÑOZ, 2019; MUÑOZ, MATEO Y ÁLVAREZ, 2014; VITÓN, 2012), siguiendo por tanto, una metodología cualitativa (TAYLOR Y BOGDAN, 1987: 19-20).

Además, con la pretensión de lograr una etnografía reflexiva, se han seguido las tres dimensiones de Dietz (2009): semántica (entrevistas etnográficas), pragmática (observaciones participantes) y sintáctica (diálogo de saberes). Asimismo, se ha usado la triangulación de datos (AGUILAR Y BARROSO, 2015; ARIAS, 2000; BETRIÁN, GALITÓ, GARCÍA, JOVÉ Y MACARULLA, 2013; DONOLO,

2 Además de otros trabajos (SÁNCHEZ, 2016; SÁNCHEZ Y MUÑOZ, 2014a; SÁNCHEZ Y MUÑOZ, 2014b; SÁNCHEZ Y MUÑOZ, 2015; SÁNCHEZ Y MUÑOZ, 2018; SÁNCHEZ Y MUÑOZ, 2020), que recogen hallazgos en ésta y otras áreas paralelas, siempre dentro del marco del aprendizaje y la práctica musical de ciegos. 
2009; RODRÍGUEZ, POZO Y GUTIÉRREZ, 2006), tanto a nivel de participantes (al aglutinar individuos, familias y colectivos) como de métodos (por medio de la entrevista en profundidad, la observación participante y no participante y el cuestionario), propiciando datos multirreferenciales (VELASCO Y DÍAZ DE RADA, 2006: 223).

Los principales instrumentos para la recogida de datos en esta investigación han sido la observación (tanto participante como no participante), el diario de campo y la entrevista (en profundidad). La muestra participante en este estudio ha integrado entrevistados tanto de España como de Argentina y Ecuador, y de diverso perfil: docentes de música en conservatorios y centros escolares con experiencia en atender alumnado de estas características, estudiantes de violín con discapacidad auditiva y sus familias, responsables de orquestas que integran músicos sordos, músicos con discapacidad auditiva y un doctor en musicología creador de algunos recursos para estos estudiantes y con experiencia en este campo. Las observaciones participantes y no participantes se produjeron a través de la experiencia docente del autor con alumnado de educación especial, trabajando durante cuatro cursos académicos en asociaciones y centros de educación especial con más de un centenar de estudiantes con discapacidad y con diversos grupos, entre los que se incluían estudiantes con discapacidad auditiva, así como otro año académico atendiendo a una alumna con deficiencia auditiva en el aula de lenguaje musical de una Escuela de Música.

\section{Resultados}

Los resultados se han focalizado en alumnado que posee resto auditivo, ya sea en mayor o menor medida, aunque se apuntan también planteamientos para estudiantes con sordera profunda. Todos ellos, han sido fruto de la etnografía, desde el estudio y revisión de estos recursos y estrategias, y su adaptación para el aula de violín en las Escuelas y Conservatorios de Música. Para una 
El Aprendizaje del Violín en Alumnado con Discapacidad Auditiva Luis Sánchez Sánchez

mejor lectura, los resultados se han distribuido en ejes o áreas temáticas que se han considerado:

- Relación y actitud con el alumnado.

- Colaboración interna y externa.

- Recursos materiales para el aula y el centro.

- Estrategias y técnicas docentes.

- Organización del aula de violín, práctica en grupo y recomendaciones para las audiciones.

A continuación, se exponen.

\section{Relación y actitud con el alumnado}

A nivel de la actitud y relación con el alumnado, las estrategias y recursos más relevantes que se han recopilado son:

- Ponerse en el lugar del estudiante con discapacidad auditiva y tratar de comprender sus dificultades: con el fin de conocer sus características y sus procesos de aprendizaje, así como los sistemas de comunicación y recursos que necesita. De acuerdo con Getzel (2008, citado en Arnaiz, 2019: 35),

Los estudiantes con discapacidad se benefician del profesorado que se preocupa y conoce sus características y necesidades, e incorpora en sus prácticas estrategias de adaptación curricular ligadas al diseño universal de aprendizaje favoreciendo así que el aprendizaje llegue a todos.

- Usar sin temor el vocabulario auditivo: no es necesario eliminar expresiones como escucha u oye, pues el propio alumnado con discapacidad auditiva también las emplea, tal y como se apreció en las observaciones con este alumnado. 
El Aprendizaje del Violín en Alumnado con Discapacidad Auditiva Luis Sánchez Sánchez

- Tratar al estudiante con naturalidad: como se haría con cualquier otro alumno, y a la vez adaptándose a sus particularidades. En palabras de Hoppenot (2000: 158), "es misión del maestro tomar al alumno tal y como es, tal y como se encuentra".

- Observar su aprendizaje y sentir motivación por conocerle y por su enseñanza: esta deficiencia, como cualquier otra, trae consigo obstáculos, por ello, la implicación y la ilusión del docente es primordial, con el fin de salvarlos y conseguir el avance del alumnado.

- El profesor debe ser concienzudo, paciente y de temperamento equilibrado. Por encima de todo, debe sentir verdadero amor y entusiasmo por su trabajo. Una buena docencia requiere un grado de devoción que el maestro será incapaz de aportar sin dedicarse a ella en cuerpo y alma (Galamian, 1998: 142).

- Tener paciencia: es la base de la pedagogía (PASCUALI Y PRÍNCIPE, 2007: 241), y en base al testimonio de Luis Fernando González, padre de Gabriel, alumno de violín con hipoacusia bilateral profunda ${ }^{3}$ del Conservatorio Nacional de Música y miembro de la Orquesta Joven de Ecuador (OJE), es un elemento fundamental:

(Aconsejo al profesor) que únicamente tenga paciencia y que investigue y utilice todos los medios que pueda considerar que le pueden ser útiles para enseñar a un niño con discapacidad auditiva, y que no piense que ese niño no lo va a lograr" (L. F. González, entrevista, 22-06-2020).

- Identificar posibles dudas, preocupaciones o problemas del estudiante: "todo profesor ha de ser un buen psicólogo", afirma Galamian (1998: 140). Por ello, es oportuno tratar estas cuestiones con el alumnado con discapacidad auditiva, manteniendo una comunicación fluida profesor-alumno.

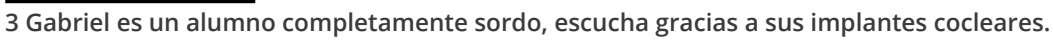


El Aprendizaje del Violín en Alumnado con Discapacidad Auditiva Luis Sánchez Sánchez

- Sensibilizar al resto del alumnado: en aquellas prácticas grupales (clases de conjunto, grupos y ensayos para las actuaciones, audiciones, actividades complementarias y extraescolares), explicando los diferentes recursos que utiliza su compañero con deficiencia auditiva. Así el resto de alumnado toma conciencia de cómo se comunican las personas sordas, favoreciendo valores como el respeto, la colaboración, la empatía, la alteridad, la convivencia y el trabajo en equipo (educación para la vida, art. 5 de la Ley Orgánica de Educación Española).

- Favorecer la motivación y autoestima del estudiante: "también habrá que planificar cuidadosamente el ánimo y el fomento de la autoestima del alumno", afirma Galamian (1998: 140). Wuytack y Boal (2009, p.49) apuntan que el entusiasmo del docente puede influir en el interés y motivación de los estudiantes de música; por ello, es indicado que el profesorado proyecte y contagie esa ilusión.

- Tratar que el estudiante disfrute: en este sentido se pronunció el profesor Fernando Camacho, que posee experiencia en atender alumnado con discapacidad auditiva: "Sobre todo le aconsejaría (al docente de violín) rebajar las expectativas. La prioridad debe ser ante todo que el alumno disfrute con lo que hace" (F. Camacho, entrevista, 25-05-2020).

- Facilitar pautas para dirigirse a este alumnado al resto del personal del centro: tanto docente como de servicios (hablarle de frente, con tranquilidad y naturalidad, llamar su atención, etc.), facilitando así su inclusión en el conservatorio y, propiciando una sensibilización en todos ellos, tal y como han señalado algunos entrevistados.

4 Ley Orgánica 2/2006, de 3 de mayo, de Educación (BOE №106 del 04-05-2006), con las modificaciones establecidas por la Ley Orgánica 8/2013, de 9 de diciembre, para la mejora de la calidad educativa (BOE N²95 del 10-12-2013). 


\section{Colaboración interna y externa}

Respecto a la colaboración interna y externa, las estrategias y recursos principales que se han reunido son:

- Colaboración de la familia: en estos casos de atención a alumnado con NEE, se hace primordial su ayuda (IPLAND Y PARRA, 2009: 460). Y en particular para los estudiantes con sordera igualmente es crucial, pues "el éxito de la educación de los niños y niñas sordos se encuentra en el trabajo cotidiano, con buenos profesionales y en colaboración con la familia", afirma Jáudenes (2004: 17).

- Recursos educativos complementarios: a los que ofrece el sistema educativo, con el fin de complementar la educación musical ordinaria. En este sentido pueden ser de utilidad cursos, masterclass, campamentos musicales o conferencias, y, dentro de lo posible, clases de apoyo adiciones a la clase ordinaria habitual. Así se desprende del testimonio del padre de Gabriel: “Además, (aconsejo al maestro) que fuera del horario de clases le dé un tiempo extra para poder corregir los errores que el estudiante pueda estar cometiendo" (L. F. González, entrevista, 22-06-2020).

- Formación continua para el docente: como señalan Moriña y Perera (2018, citado en Arnaiz, 2019: 36), "la actitud del profesorado mejora una vez que éste se forma y cuenta con más experiencia sobre cómo responder a las necesidades de los estudiantes con discapacidad". Esta formación puede venir de las diversas Federaciones, Asociaciones y Confederaciones para Sordos, que suelen realizar iniciativas para los docentes, así como de los centros de recursos de formación del profesorado.

- Alumno tutor o enlace: de acuerdo con las propuestas escolares de Durán y Miquel (2003, p.75), se propone 
esta figura, para que pueda ayudar al alumnado con discapacidad auditiva o incluso con cualquier otra deficiencia en el centro, tanto en determinadas prácticas en grupo (permitiendo al alumnado sordo trabajar en equipo y contar con una guía) como a nivel externo (a través de la cotutoría o tutoría entre alumnos, práctica frecuente en el ámbito escolar, y que sirva como apoyo para la clase individual). Un ejemplo puede ser en prácticas grupales contar con el apoyo del compañero de atril (Hash, 2003). De esta forma, se involucra al alumnado en las acciones inclusivas, siendo de esta forma responsable de su propio aprendizaje y también del de los demás (DURÁN Y MIQUEL, 2003: 76). Así se desprende también del testimonio de Luis Fernando González, padre de Gabriel, alumno de violín con discapacidad auditiva en Ecuador:

"Como apoyo únicamente el de nosotros, sus padres. El maestro utilizaba el método Suzuki para enseñar el violín, y también contaba con el apoyo de sus alumnos más grandes para corregir los errores de los alumnos más pequeños" (L. F. González, entrevista, 22-06-2020).

- Apoyo de las Asociaciones, Federaciones y Confederaciones para Sordos: en especial aquella en la que esté el alumno en contacto o afiliado. Estos organismos muestran predisposición y colaboración con los docentes, como se comprobó en el trabajo de campo desarrollado, y disponen de especialistas específicos, con los cuales, el profesorado puede compartir las dudas que se tienen, ideas sobre recursos y materiales, etc. También suponen un apoyo para el propio estudiante, tal y como se expone en este testimonio del músico DJ José Ramón Solórzano, que tiene hipoacusia del $100 \%$ en ambos oídos: 
"He ido a rehabilitación de Logopedia tanto al hospital por la seguridad social durante más de un año, así como después a Acopros, la asociación de sordos de la que soy usuario. Hacemos todo tipo de ejercicios para mejorar la discriminación de sonidos del procesador del implante" (J. R. Solórzano, entrevista, 09-062020).

En esta línea de ejercicios y de rehabilitación auditiva, también se pronunció el padre de Gabriel, estimando que es necesaria para el estudio musical: "Considero que para que a un niño sordo usuario de implantes cocleares le vaya bien en la música, debe tener una muy buena rehabilitación auditiva, desde sus inicios" (L. F. González, entrevista, 22-06-2020).

- Apoyarse en el equipo directivo y el claustro: propiciando una colaboración y coordinación por parte de los docentes del centro, siguiendo los planteamientos de Durán y Miquel (2003, p.75) y de Arnaiz (2019: 36-37):

Ya no son los profesores especialistas los principales y únicos responsables, como en épocas anteriores, de los alumnos con necesidades de apoyo educativo, sino que todo el profesorado es responsable de la atención a la diversidad en los centros. Todos están obligados a dar una respuesta educativa acorde a las necesidades del alumnado tengan o no dificultades, puesto que las aulas son los espacios por excelencia donde todos los alumnos deben encontrar una respuesta educativa óptima a su manera de ser y de aprender (Arnaiz, 2019: 36-37).

\section{Recursos materiales para el aula y el centro}

Los recursos materiales que se han recopilado para el trabajo con el alumnado con deficiencia auditiva son: 
- Teléfono móvil o grabadora de video: para que pueda grabar la clase y posteriormente volver a escucharla para asimilar y/o revisar todos los detalles. La profesora de lenguaje musical Pilar Mercader indicó que el estudiante con discapacidad auditiva que atiende, "a través de su tablet, escucha mejor que en directo los sonidos" (P. Mercader, entrevista, 26-05-2020), experiencia que extrajo durante las clases online debido al estado de alarma por el COVID-19. Esta medida es aconsejable también para el resto de alumnado de violín: "Grabando el tiempo de clase con el profesor y escuchándolo después en la casa, se podrán captar mejor todas las explicaciones, sin que se quede absolutamente nada en el tintero", afirma Claudio (1999: 163).

- Implante coclear, audífono o equipo FM: los cuales también utilizará en sus enseñanzas obligatorias, y que propiciará que pueda seguir mejor las clases, tal y como se comprobó en las observaciones con estos estudiantes y en las entrevistas.

- Numerofonía de Aschero: se trata de un lenguaje inclusivo tanto para las personas que tienen resto auditivo como sordera profunda basado en colores y formas geométricas creado por el Dr. Sergio Aschero (figura 2), el cual ha trabajado con niños y adolescentes sordos, y que resulta efectivo para la atención de este alumnado en el área de música (S. Aschero, entrevista, 16-04-2020). En la siguiente figura se aprecia una comparativa de la numerofonía con la tactofonía, ésta última dirigida a deficientes visuales y también creada por el Sr. Aschero: 
El Aprendizaje del Violín en Alumnado con Discapacidad Auditiva Luis Sánchez Sánchez

\section{Figura 2 - Numerofonía y Tactofonía de Aschero}

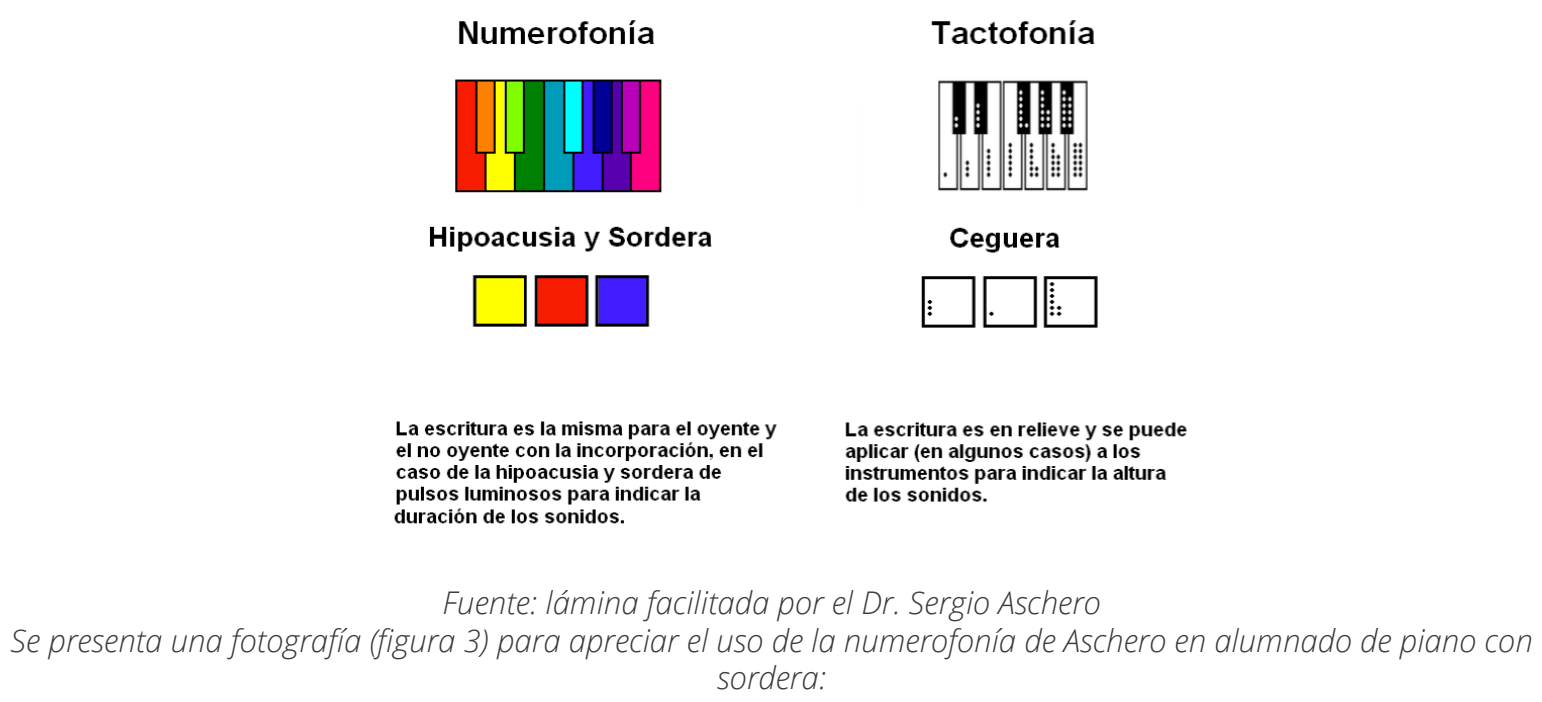

Figura 3 - Alumnado de piano con sordera utilizando la numerofonía de Aschero

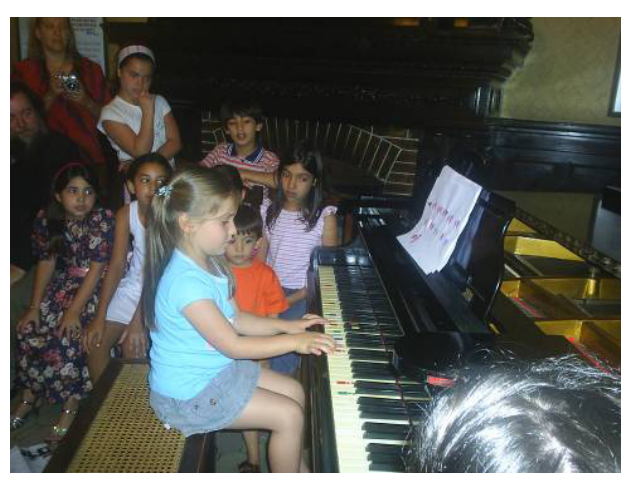

Fuente: fotografía facilitada por el Dr. Sergio Aschero

Descripción de la imagen: Talleres que realizó el Sr. Aschero en Uruguay en 2005.

- Materiales visuales y/o luminosos: como pueden ser esquemas $y / 0$ colores que anticipen $y / 0$ apoyen los diferentes contenidos, y que refuercen las referencias auditivas, como se desprende de las experiencias del Sr. Aschero:

“He trabajado con niños y adolescentes sordos y por supuesto que los estímulos lumínicos producen en la lectura y ejecución instrumental y vocal una mayor y a veces perfecta relación con lo 
El Aprendizaje del Violín en Alumnado con Discapacidad Auditiva Luis Sánchez Sánchez

temporal. Recuerda que la vista es el $83 \%$ de nuestra percepción y el oído el $11 \%$. Todos los alumnos tienen el derecho de poder leer y percibir táctilmente la música, así como lo tienen que hacer lo mismo con los textos" (S. Aschero, entrevista, 13-04-2020).

- Recursos visuales específicos para los primeros cursos: como pueden ser la lectura de notación empleando colores (Colourstrings), violines de goma (figura 4), juegos rítmicos con el arco basados en el movimiento, pegatinas de colores o plantillas en el suelo para la colocación de los pies, tal y como se desprende de las experiencias del profesor de violín Álvaro López cuando atendió a un alumno de iniciación con pérdida auditiva severa que utilizaba implante coclear:

"Estas clases de violín para edades muy tempranas están basadas fundamentalmente en el juego y se apoyan en una gran variedad de recursos (colores, plantillas, dibujos, etc.), lo que facilitó bastante la adaptación de las actividades realizadas con el resto de compañeros" (A. López, entrevista, 13-05-2020).

Figura 4 - Estudiantes de violín utilizando violines de goma

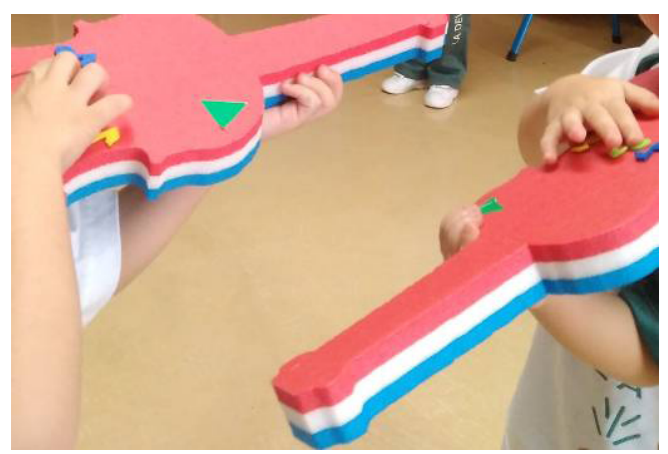

Fuente: fotografía facilitada por Álvaro López

Descripción de la imagen: clase del Sr. López en que atendía un alumno con discapacidad auditiva.

- Metrónomo y afinador con apoyos luminosos: tanto al marcar los pulsos (el primero), como en la indicación tonal con colores (el segundo) $)^{5}$, como se comprobó en las observaciones con este alumnado.

5 La mayoría de los actuales que hay en el mercado lo suelen tener, aunque conviene vigilar que el alumnado adquiera uno de este perfil. 
- Círculos de metal para el diapasón: se trata de un recurso para alumnado con ceguera aconsejado por el Sr. Aschero (figura5)quefacilitalaubicación delas notas en loscomienzos (SÁNCHEZ, 2017: 277). Cuenta con un planteamiento propio creado por el Dr. Sergio Aschero empleando su tactofonía y que, a través de su propia experiencia con alumnos sordos, también resulta interesante para el trabajo con alumnado con deficiencia auditiva (S. Aschero, entrevista, 11-04-2020). El profesor Álvaro López señaló que también empleaba marcas en el diapasón para la colocación de los dedos (A. López, entrevista, 13-05-2020). E igualmente, desde la asignatura de lenguaje musical, la profesora Pilar Mercader le parece aconsejable un recurso en este sentido, en concreto pegatinas, para el correcto desarrollo del oído:

“El consejo que puedo dar (a los docentes de violín) es que fomenten la memoria muscular y espacial y se apoyen en las pegatinas para que en los primeros cursos el alumnado pueda saber qué nota está sonando y eso le ayude a formar su oído interno" (P. Mercader, entrevista, 26-05-2020).

Mostramos una ilustración sobre cómo podrían ubicarse estos círculos de metal que se proponen, reflejando las diferentes ubicaciones de los dedos sin concretar la nota resultante (como si hace la tactofonía de Aschero).

Figura 5 - Círculos de metal para 1ª posición (semitonos dedos 2-3)

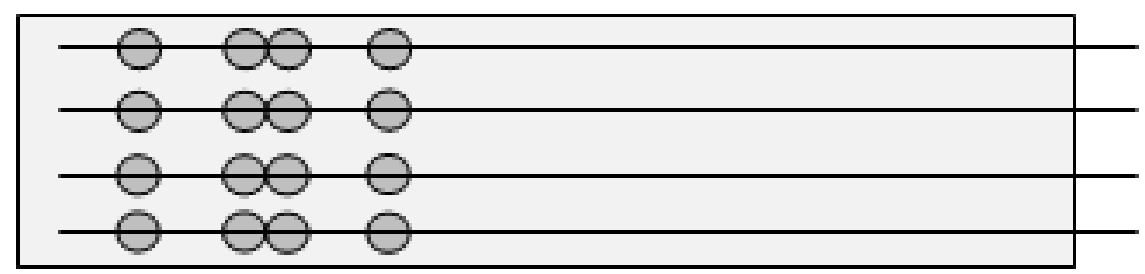

Fuente: elaboración propia. 
El Aprendizaje del Violín en Alumnado con Discapacidad Auditiva Luis Sánchez Sánchez

- Recursos tecnológicos específicos: que puedan ser necesarios, no solo para la propia práctica del violín, sino también para las actividades complementarias y extraescolares como bucles magnéticos individuales, equipo FM u otras ayudas técnicas portátiles que propician la comunicación e información del alumnado con deficiencia auditiva (JÁUDENES, 2007: 7-8), además de recursos tecnológicos para su propia escucha musical personal y vida diaria. El músico DJ con discapacidad auditiva José Ramón Solórzano indicó los siguientes recursos que utiliza:
"Dispongo de dos accesorios para conectarme y escuchar mejor. Por un lado, el Mini Mic+2, que funciona cómo micrófono inalámbrico y también se puede conectar mediante cable a una TV, móvil, equipo de música, mesa de sonido, etc. Y de ahí va directa e inalámbricamente al implante. (...). Por otro lado, el Phone Clip, que conecta al implante inalámbricamente todo lo que disponga de salida de Bluetooth. TV, móvil, ordenador, etc." (J. R. Solórzano, entrevista, 09-06-2020).

- Recursos para el centro: para sus dependencias comunes como avisos luminosos, paredes y puertas acristaladas, megafonía, paneles informativos y de señalización, o tablón de anuncios con información detallada y actualizada, así como soportes informáticos accesibles y una web accesible cuyo contenido favorezca la inclusión (JÁUDENES, 2007: 13).

\section{Estrategias y técnicas docentes}

Las estrategias y técnicas docentes que se han reunido para la atención del alumnado con discapacidad auditiva en la asignatura de violín son: 
- Enseñanza individualizada: "todo debe adaptarse a las necesidades individuales de cada persona", afirma Galamian (1998:141). De esta forma, modificar los planteamientos que sean necesarios, alcanzando igualmente los objetivos. Este aspecto es relevante, ya que al alumnado con discapacidad auditiva hay contenidos que puede costarle más o incluso el doble, tal y como señala el padre de Gabriel: "Sí, en realidad (el estudio y práctica de la música para un alumno sordo) es muy complejo, ya que le toma el doble de tiempo que a un niño oyente" (L. F. González, entrevista, 22-06-2020). Además, esta cuestión tiene su respaldo a nivel normativo en el territorio español, pues el Real Decreto 1577/2006 que recoge aspectos básicos del currículo para las enseñanzas profesionales de música señala en su disposición adicional 3.2. (p.2.857): “Las Administraciones educativas adoptarán las medidas oportunas para la adaptación del currículo a las necesidades del alumnado con discapacidad".

- Entrenar el resto auditivo del alumnado: así que pueda aprovecharlo de la manera más efectiva, ayudándole a la identificación de los sonidos y en la corrección de la afinación, ya que la audición ocupa un lugar crucial en el aprendizaje de la música (WUYTACK Y BOAL, 2009: 43). En estas actividades, el docente deberá tener en cuenta adaptar las actividades a las capacidades auditivas del estudiante:

"Otras actividades relacionadas con la audición, como identificación de notas o audición y repetición de fragmentos melódicos, que buscaban el desarrollo del oído interno, sí que requerían de la audición, y por lo tanto fueron actividades a las que presté especial atención por si se necesitara algún tipo de adaptación. En su mayor parte el alumno pudo desenvolverse sin problema alguno y solo en casos puntuales hube de adaptar mínimamente la actividad (por ejemplo, en el reconocimiento auditivo de sonidos proporcionándole opciones más 
reconocibles entre las que escoger -notas separadas por más de una tercera-)" (A. López, entrevista, 13-05-2020).

- Desarrollar la memoria auditiva y la entonación: ya que supone una herramienta de ayuda para los músicos con deficiencia auditiva, y a la vez la entonación, debido a la difícil percepción de las alturas musicales por parte de los sordos. En este sentido se pronunciaron tanto el DJ José Ramón Solórzano como el padre de Gabriel:

“Al ser sordo postlocutivo y DJ tantos años, la memoria auditiva me ayudado muchísimo en la rehabilitación y discriminación de las palabras y sonidos. Ha sido una gran ventaja conocer tanta música a lo largo de los años. Al principio hasta era difícil identificar algunos temas musicales ya conocidos antes de mi diversidad auditiva. Pero con la rehabilitación, trabajo, paciencia y tiempo ya soy capaz de identificar hasta canciones nuevas hace unos años" (J. R. Solórzano, entrevista, 09-06-2020).

"Como recursos utilizaba el copiar bien las notas que el profesor escribía en la pizarra, luego memorizarlas, y en lo posible cantarlas" (L. F. González, entrevista, 22-06-2020).

- Apoyos y metodologías específicas: si el alumnado con discapacidad auditiva tiene especiales dificultades, pueden utilizarse apoyos como notas guía, y metodologías como la fononimia, tal y como aconseja la profesora Pilar Mercader:

\footnotetext{
“Decidí escribir unas notas guía cada dos compases y algunas pistas sobre el ritmo musical y de esta forma, con la referencia sí que va mejorando y es capaz de distinguir alturas y direcciones de las melodías. (...). También se realiza en clase fononimia para ayudarle a distinguir el movimiento de la melodía" (P. Mercader, entrevista, 26-05-2020).
} 
- Desarrollar la estimulación vibrotáctil y la tactoaudición: en especial en aquel alumnado sin apenas resto auditivo o sordera profunda, con el fin de compensar la información auditiva (MOSTEYRÍN, 2009).

- Enseñar a estudiar: es básico para el estudio del violín (CLAUDIO, 1999: 159; GALAMIAN, 1998: 125; PASCUALI Y PRÍNCIPE, 2007: 153), y es uno de los defectos principales que poseen los estudiantes (CLAUDIO, 1999: 159). Por ello, y dada las dificultades que ya tiene el alumnado con discapacidad auditiva, se deben aconsejar unas claras recomendaciones para que aproveche y estructure correctamente su estudio.

- Potenciar el trabajorítmico:yaquela carencia de información auditiva no solo repercute en el ámbito melódico, sino que también afecta al ritmo, debiendo utilizar, en caso de que el alumnado con discapacidad auditiva tenga especiales dificultades, apoyos como referencias rítmicas, ostinatos o ejercicios de percusión corporal, como recomienda la profesora Pilar Mercader:

"Este alumno tiene serias dificultades a la hora de realizar los dictados, tanto en el ritmo como en la altura de las notas. También en la parte rítmica, he observado que tiene problemas cuando aparecen negras. (...). Opino que un apoyo sonoro como bases de acompañamiento con ostinato son muy útiles, así como ejercicios de percusión corporal para que sea consciente del ritmo no solamente oralmente, sino percutiendo, más cercanamente a los instintos y a lo palpable" (P. Mercader, entrevista, 26-05-2020).

- Aprendizaje significativo: para los estudiantes, la realidad y el contacto con lo cercano supone un interés y motivación, y más aún en el alumnado con NEE (AGUADED E IPLAND, 1998: 213). 
- Para las explicaciones orales, y desde la realidad que se conoció en las observaciones con este alumnado, deben seguirse los siguientes consejos para favorecer la comunicación:

Cuando se quiera dirigir al alumno con deficiencia auditiva o se desee darle alguna indicación, si no se ha dado cuenta, se debe llamar su atención con una señal (HASH, 2003). Por ejemplo, dentro del aula de violín puede ser efectivo un toque ligero sobre su brazo u hombro, o alguna señal visual como levantar el brazo.

"No se debe hablar nunca sin que el alumnado sordo nos pueda mirar (HASH, 2003), por ello, si se está escribiendo algo en la partitura o en la pizarra, se debe hacer una pausa e iniciar o retomar el discurso posteriormente. Igualmente, a la inversa, se debe esperar a que se retome el contacto visual para comenzar a hablar.

» Para facilitarle la lectura de labios y la comprensión del mensaje, se debe tener en cuenta algunas recomendaciones al hablar como situarse a su misma altura, vocalizar bien (sin exagerar ni gritar), hablar con un ritmo tranquilo, no ponerse la mano o el violín delante de la boca, elaborar un discurso con frases cortas y palabras conocidas, evitar tecnicismos si el estudiante no los conoce así como exposiciones orales muy largas, cuidar que la cara esté a plena luz (nunca de espaldas a la luz o las ventanas) o utilizar medios visuales para complementar la información verbal (MONFORT, 2004: 354).

» Si el alumnado no llega a entender el mensaje se le debe repetir usando gestos, dibujos, escribiendo la palabra o diciendo el mismo aviso con frases y palabras más sencillas.

» Situar la conversación a nivel temporal y/o de lugar para que el alumnado entienda mejor el mensaje, por ejemplo: "Esta semana debemos estudiar los ejercicios de mano 
derecha" o "Mañana a las 18:00 h., será la Audición en el Salón de Actos".

»En caso de clase grupal, es preciso respetar los turnos de palabra, indicando quién va a intervenir y fomentar un ambiente de silencio, para que el alumnado con deficiencia auditiva escuche perfectamente las intervenciones.

- Desarrollar la concentración: es una necesidad para el estudio del violín (GALAMIAN, 1998:125), pero en alumnado con discapacidad auditiva es primordial, para que esté pendiente del sonido y de las referencias auditivas. Para potenciarla conviene vincularla con otro aspecto destacado en la práctica musical como es la respiración, pues ambos elementos pueden conectarse (CLAUDIO, 1999: 167; MENUHIN, 1987: 139). "Respirar correctamente es muy importante para concentrarnos bien", afirma Claudio (1999: 167).

- Señales visuales: considerando un código con las más fundamentales para el aula, no teniendo temor de usar todo tipo de gestos, señales o ayudas visuales, pues el alumnado con sordera tiene costumbre de emplearlas (HASH, 2003). Y siempre cuidando que sean visibles para el alumno con discapacidad auditiva, tal y como aconseja el coordinador de la JOGC: "Los recursos son los mismos que con un estudiante de música oyente, solo necesita que sus gestos sean visibles y que no haya nada que dificulte la visión de sus gestos o sus labios" (T. Vargas, entrevista, 1405-2020). A modo de ejemplo se proponen las siguientes: 
El Aprendizaje del Violín en Alumnado con Discapacidad Auditiva Luis Sánchez Sánchez

\section{Tabla 1 - Señales visuales propuestas para el aula de violín}

\begin{tabular}{|l|l|}
\hline \multicolumn{1}{|c|}{ SEÑAL } & \multicolumn{1}{c|}{ SIGNIFICADO } \\
\hline Dedo índice hacia arriba & $\begin{array}{l}\text { Subir afinación (está bajo el pasa- } \\
\text { je/la nota) }\end{array}$ \\
\hline Dedo índice hacia abajo & $\begin{array}{l}\text { Bajar afinación (está alto el pasa- } \\
\text { je/la nota) }\end{array}$ \\
\hline Mano hacia arriba & Tocar más fuerte \\
\hline Mano hacia abajo & Tocar más piano \\
\hline $\begin{array}{l}\text { Dedos pulgar/índice casi } \\
\text { juntos }\end{array}$ & Golpe de arco más corto \\
\hline $\begin{array}{l}\text { Dedos pulgar/índice separa- } \\
\text { dos }\end{array}$ & Golpe de arco más largo \\
\hline $\begin{array}{l}\text { Señalar con el arco un pasaje } \\
\text { de la partitura }\end{array}$ & $\begin{array}{l}\text { Fragmento que se desea repasar/ } \\
\text { repetir }\end{array}$ \\
\hline
\end{tabular}

Fuente: elaboración propia.

- Emplear una metodología abierta: tal y como aconseja el profesor Álvaro López a un docente de esta especialidad que deba atender alumnado de estas características:

"Le recomendaría que no se limitase a seguir las mismas técnicas y ejercicios que usa con el resto del alumnado, que no tenga miedo de innovar y de probar nuevas actividades, y que trate de abordar la enseñanza desde diversas perspectivas utilizando toda la multiplicidad de recursos a su alcance. Esto no significa que cuantos más recursos use mejor será la calidad y los resultados del proceso de enseñanza-aprendizaje, sino que es posible que se obtengan mejores resultados con algún recurso en concreto, con una actividad diferente o que determinada técnica pueda realizarse de una forma alternativa, y la única forma de descubrir esto es probando (y equivocándose también)" (A. López, entrevista, 13-05-2020).

- Incrementar los ejemplos visuales con el instrumento: en lugar de demasiada explicación oral, mostrando así las diversas cuestiones técnicas, lo que permite una mejor 
El Aprendizaje del Violín en Alumnado con Discapacidad Auditiva Luis Sánchez Sánchez

asimilación, tal y como se apreció en las observaciones con estos estudiantes.

- Seguir una metodología participativa: propiciando así la reflexión, el diálogo, el pensamiento y la participación del alumno. En palabras de Pascuali y Príncipe (2007: 107), “desarrollar el espíritu de observación, imitación y reflexión. Se aprende mirando, oyendo y pensando".

\section{Organización del aula de violín, práctica en grupo y re- comendaciones para las audiciones}

A continuación, se presentan algunas recomendaciones a nivel de la organización del aula de violín, las cuales, son extrapolables para el estudio en casa, así como para otras aulas del Conservatorio en que el estudiante con deficiencia auditiva reciba también clases (lenguaje musical, armonía, análisis, música de cámara, orquesta, coro, etc.), y que se comprobó en las observaciones y entrevistas:

- Colocarse cerca del alumno: con el fin de que escuche perfectamente las indicaciones, tal y como como muestra este testimonio del profesor Álvaro López: “La primera medida específica fue el tratar de colocarme siempre cerca del alumno, en una posición en la que me pudiese ver y oír con facilidad" (A. López, entrevista, 13-05-2020). De forma similar se pronunció el coordinador de la JOGC: "Que el campo entre el profesor y el alumno esté libre para que el alumno pueda visualizar claramente lo que quiere transmitir el profesor" (T. Vargas, entrevista, 14-05-2020).

- Ventanas y puertas cerradas: cuando sea posible, así se favorece un mayor ambiente de silencio y que le lleguen mejor las referencias auditivas al estudiante con discapacidad auditiva. 
- Aula con buena acústica: que tenga buena sonoridad y cuente con paneles de corcho en las paredes, propiciando un aislamiento acústico y que no haya reverberaciones ni distorsiones del sonido. Hash (2003) propone utilizar alfombras, cortinas o tapizados que favorecen la amortiguación del sonido.

- Aula con buena iluminación: para que las diversas señales visuales se aprecien perfectamente.

- Sistemas de calefacción, aire acondicionado y tubos de luz lo más silenciosos posible: para que no perturbe la escucha del alumno (HASH, 2003).

- Amortiguar los ruidos de sillas y mesas: evitando moverlas, o colocándoles esponja o fieltro en sus patas, como refleja este testimonio del docente Álvaro López: “También trataba de mantener y controlar el ruido de la clase, en la medida en la que esto se puede lograr" (A. López, entrevista, 13-05-2020).

En caso de práctica en grupo de cámara, se debe organizar la disposición de forma que el alumnado con deficiencia auditiva tenga contacto visual con todos sus compañeros y esté cerca de los otros músicos (HASH, 2003), y a la vez esté próximo al docente y/o del piano (en caso de práctica con el profesor pianista acompañante). También resulta óptimo facilitar las partituras de los acompañamientos de las piezas musicales. Esto genera más seguridad, confianza y autonomía en las entradas, compases de espera, etc. sobre todo en caso de que el grado de deficiencia auditiva sea bastante elevado, tal y como se comprobó en las observaciones con este alumnado.

Por otro lado, si el docente dirige el grupo de cámara durante los ensayos o el propio concierto, debe hacer unos gestos adaptados y más exagerados que los habituales, como expuso el profesor Fernando Camacho: 


\begin{abstract}
“De todos modos, como director de la agrupación me apoyo mucho de los gestos y la comunicación visual, muchos de estos gestos no tienen nada que ver con la técnica convencional de un director de música, ya que utilizo en muchos casos un lenguaje gestual adaptado a ellos. Los movimientos de los brazos son mucho más exagerados que cuando diriges a músicos oyentes, al igual que los gestos a la hora de expresar el carácter musical de un fragmento en concreto" (F. Camacho, entrevista, 25-052020).
\end{abstract}

Además, para el alumnado que utiliza audífono conviene tener en cuenta que los sonidos muy fuertes pueden ser molestos, por lo que será quizás necesario durante la práctica grupal apagar el audífono, previa consulta a un especialista (HASH, 2003).

Por último, respecto a las audiciones, además de vencer la extrañeza al público realizándolas periódicamente (CLAUDIO, 1999: 166), surge en estos alumnos la dificultad de en acústicas complicadas, las referencias auditivas no sean las mejores y les resulte más difícil la interpretación. Será por tanto necesario el ensayo previo o la prueba acústica en la sala. Además, en caso de tocar en grupo de cámara junto con otros alumnos, conviene juntarles mucho, y hacer lo mismo de cara a la actuación con el profesor pianista acompañante, de esta forma, el alumnado con deficiencia auditiva escucha lo mejor posible los otros instrumentos, y ante problemas que surjan durante la interpretación, las posibles señales visuales que se realicen son mejor apreciadas por todos los miembros.

\title{
Discusión y Conclusiones
}

Atendiendo a las preguntas de investigación formuladas en la introducción y con los resultados obtenidos, se confirma que sí que es posible aportar alguna herramienta que potencie la inclusión del alumnado con discapacidad auditiva en el aula de 
violín, contestando así a la primera de las cuestiones formuladas. Sin embargo, los propios resultados confirman que no es necesario un programa o repertorio específico para la atención de estos estudiantes (tal y como la segunda pregunta de investigación planteaba), sino adaptaciones individuales y a nivel metodológico, pudiendo de esta forma el alumno con deficiencia auditiva seguir el mismo programa y repertorio violinístico de sus compañeros.

Valorando los resultados, se extrae también que pueden superarse las dos dificultades que se expusieron en la introducción, en este caso el hecho de no disponer con plenas facultades del oído para el aprendizaje de un instrumento musical y las problemáticas específicas que presenta el estudio del violín, ya que los recursos, materiales, técnicas, actividades, estrategias y buenas prácticas recopiladas contribuyen a ofrecerles respuesta y a favorecer la inclusión de estos estudiantes.

Dicho esto, este estudio ha concretado unos resultados generales. Por ello, probablemente, como futura línea de investigación pueda ser enriquecedor ampliarlo, desglosarlo por niveles, y concretarlo para todas las asignaturas que integran estas enseñanzas (lenguaje musical, orquesta, armonía, análisis, historia de la música, etc.) ya que, si bien se han recogido algunos recursos y estrategias también para ellas, no se ha profundizado en estas materias.

Dentro del proceso de investigación de este trabajo, se han creado también espacios de reflexión y diálogos de saberes sobre la formación y aprendizaje de este alumnado con discapacidad auditiva. Uno de los puntos que se extrajeron y que en estas conclusiones merece ser apuntado, es la necesidad de ofrecer una enseñanza personalizada a estos estudiantes. En este sentido, opinó el profesor de violín Álvaro López:

“Es obvio que el estudio y práctica de la música para un alumno con discapacidad auditiva difiere sustancialmente de otro sin problemas de audición... Al no percibir los estímulos sonoros de la misma manera que otros alumnos, se necesitará una 
adaptación de la forma de enseñanza y un esfuerzo significativo por parte del alumno. Sin embargo, todos los alumnos, tengan una discapacidad auditiva o no, requieren de una adaptación personalizada de la forma en la que les enseñamos (cada uno percibe la música de una forma distinta, tiene inquietudes diferentes y cuerpos únicos), por lo tanto, las discapacidades auditivas no dejan de ser una característica más a la que los docentes se han de adaptar" (A. López, entrevista, 13-05-2020).

En cuanto al objetivo principal de la investigación, se considera que se ha cumplido, ya que estos resultados, facilitan la enseñanza de violín del alumnado con discapacidad auditiva en los centros de música, gracias a los recursos, estrategias y buenas prácticas que concretan, los cuales, al surgir desde la realidad de estos escenarios y las dificultades que presentan estos estudiantes que se han conocido, tienen realismo, respaldo, fiabilidad, solidez y viabilidad.

Por otro lado, con esta investigación, se contribuye en un área en la cual algunos docentes de instrumento son reacios a la enseñanza de estos alumnos debido a algunas inquietudes (HASH, 2003), o incluso también para resolver posibles dudas del profesorado, como muestra este testimonio: "Creo que sería necesaria la creación de algún método o metodología que sirviese de guía a los profesores de instrumento a la hora de abordar la enseñanza al alumnado con discapacidad auditiva" (A. López, entrevista, 13-05-2020). A través de los resultados, por tanto, se facilitan recursos, estrategias y buenas prácticas didácticas dentro del ámbito de la pedagogía del violín, incrementando así los trabajos ya existentes que se han citado en la introducción, como los de Montoya (2014) dirigido a la flauta dulce, de Mosteyrín (2009) sobre la técnica de la tactoaudición o el de Hash (2003) acerca de la enseñanza instrumental de los sordos, entre otros.

A nivel reflexivo, se desprende también de la investigación que la música es importante y que todos los estudiantes merecen ser educados musicalmente, incluidos los sordos, tal y como 
señala Darrow (1993, p.109). El trabajo de campo corroboró esta cuestión, destacando además el papel de la práctica grupal para este alumnado, como muestran los testimonios de estos docentes:

"El hecho de que los alumnos se sientan parte de un grupo es muy importante, tanto en su desarrollo personal como cognitivo. Los beneficios de la enseñanza musical son los mismos tanto para alumnos oyentes como sordos. El respeto, la confianza en sí mismo, la expresión de las emociones, la importancia del silencio, etc." (F. Camacho, entrevista, 25-05-2020).

“En el caso concreto de este alumno, pude observar la ilusión y la alegría con la que afrontaba las clases. Disfrutaba de la música (escuchándola y haciéndola) y lo hacía mucho más si cabe en las actividades grupales que implicaban tocar junto con sus compañeros. Es por esto por lo que creo que, de forma general, el estudio de la música es beneficioso para el alumnado con discapacidad auditiva, pues les proporciona una herramienta más para relacionarse y disfrutar del mundo que les rodea" (A. López, entrevista, 13-05-2020).

En esa línea de que la música puede ser una herramienta para que el alumnado con discapacidad auditiva pueda relacionarse, también se pronunció la profesora Pilar Mercader, considerando que es positivo para estos estudiantes, así como también Luis Fernando González, valorando el papel de la música en el desarrollo de su hijo:

“Creo que la música favorece a la socialización, porque los problemas auditivos son causantes del aislamiento de las personas en muchas ocasiones y además genera emociones positivas en las personas que participan en las actividades musicales. En mi opinión sí es interesante y positivo que este alumnado estudie música" (P. Mercader, entrevista, 26-05-2020). "Sí, muy positivo (haber conocido la música) en todos los aspectos, ya que eso le enseñó que no hay imposibles en la vida 
cuando uno ama lo que hace, además de que le ha permitido ser más sociable, a trabajar en grupo, a vencer las adversidades" (L. F. González, entrevista, 22-06-2020).

Incluso, esta perspectiva, puede ser también extrapolable a otras capacidades, tal y como opinó el músico DJ con deficiencia auditiva José Ramón Solórzano: "La música hace disfrutar a cualquier persona independientemente de su diversidad funcional" (J. R. Solórzano, entrevista, 09-06-2020).

Entre los elementos destacados para el desarrollo musical de este alumnado, se ha confirmado que uno de ellos es la colaboración familiar, tal y como algunos autores defienden (IPLAND Y PARRA, 2009; JÁUDENES, 2004). Asimismo, a través de este trabajo se trata de ofrecer solución y respuesta a la atención del alumnado con discapacidad auditiva desde el aula de violín. Pero, para que esta atención sea efectiva, además de conocer y utilizar los recursos pertinentes, también es preciso una serie de estrategias y técnicas docentes por parte del profesorado: "No basta con dotar a los alumnos con medios, se requiere también una adaptación del estilo del profesorado", afirma Monfort (2004: 354). A través de los resultados que se han concretado, se aporta en estos dos aspectos.

Dentro de los resultados se ha actuado también en diferentes ámbitos de la asignatura, con el objetivo de facilitar la inclusión, incluyéndose recursos específicos para la afinación, tan determinante en este instrumento y teniendo en cuenta las dificultades que tiene para este alumnado no escuchar con plenas facultades las referencias sonoras. Y se han concretado también diversos recursos tecnológicos para atender esta discapacidad, ya que como se dijo en la introducción, las nuevas tecnologías ofrecen ventajas para la atención de este alumnado. Pero se ha apreciado que es un campo que está en continua evolución y crecimiento, como muestran estos testimonios: 
"Naturalmente como he dicho antes, el estudio y práctica de la música para un alumno sordo es diferente. Tenemos que partir de las experiencias previas que hayan tenido con la música. Quizás la parte que haya que desarrollar más, sea la parte de la entonación y la altura de los sonidos, ya que es la de más difícil percepción por parte de estos. Afortunadamente está habiendo muchos avances tecnológicos que ayudarán en un futuro a que el estudio musical de los alumnos sordos sea más fructífero" ( $F$. Camacho, entrevista, 25-05-2020).

“En el caso de la (discapacidad) auditiva, los audífonos, implantes y accesorios para ambos oídos son una gran ayuda. Así cómo las vibraciones para los que no disponen de estas prótesis, poniendo la mano u otra parte del cuerpo cerca del altavoz para notarlas. Ahora hay también unos chalecos vibratorios que se conectan a las mesas de sonido transmitiendo inalámbricamente la señal a estos y los diversos auditivos pueden recibir las vibraciones entre el pecho y la espalda" (J. R. Solórzano, entrevista, 09-062020).

Otra reflexión que esta investigación deja, es que queda camino para normalizar la participación de los músicos con discapacidad auditiva, así se desprende del testimonio del coordinador de la JOGC:

“La música favorece enormemente a los discapacitados auditivos como a los oyentes. Actualmente no hay grandes diferencias entre oyentes y sordos, gracias sobre todo a los implantes cocleares, el problema es que la mayoría de las personas cuando ven actuar a músicos sordos se sorprenden lo que indica que aún queda mucho trabajo que hacer para normalizar está situación" (T. Vargas, entrevista, 14-05-2020).

Además, la investigación ha propiciado espacios de reflexión con protagonistas de esta área. Espacios, que siguen abiertos y propician una continua reflexión de la praxis-teoría, y que son 
El Aprendizaje del Violín en Alumnado con Discapacidad Auditiva Luis Sánchez Sánchez

valiosos para la investigación docente, pues posibilitan la reflexión y la mejora de la misma.

La investigación también confirma que la atención a este alumnado, si bien presenta dificultades, también deja en el maestro un aprendizaje profesional y docente valioso, como muestran los testimonios de estos profesores:

"Considero muy positiva esta experiencia. Para mí fue un reto muy satisfactorio, pues como acabo de comentar, el ver los progresos del alumno y notar la ilusión con la que afrontaba las clases, compensa con creces el trabajo de adaptación y de búsqueda de una metodología adecuada" (A. López, entrevista, 13-05-2020).

"Para mí personalmente, trabajar con alumnos sordos ha sido y está siendo una de las mejores experiencias como profesional de la enseñanza musical, sobre todo cuando estos descubren, que sí es posible disfrutar de una actividad de la que erróneamente aseguraban no ser capaces. Observarles y ver el desarrollo en el tiempo es verdaderamente gratificante" (F. Camacho, entrevista, 25-05-2020).

Y, además también deja en el profesorado un aprendizaje humano y personal enriquecedor, como la docente Pilar Mercader indicó: "Creo que ha sido una experiencia grata acerca de la superación, el trabajo y la mejora de este alumnado que cada día intenta superarse y progresar" (P. Mercader, entrevista, 26-05-2020).

Por otro lado, esta investigación pone de manifiesto la importancia de la riqueza de la diversidad y el derecho a ser diferentes, valores que desde la escuela se hace necesario favorecer, pues como afirma Vlachou (1999: 40), el objetivo "es comprender que vivimos en un mundo de diferencias y que la lucha consiste en integrar las mismas. En un mundo lleno de diferencias, la normalidad no existe". 
También se extrae, que sería interesante que en los centros de música existiera una red de apoyo similar a la que se dispone en los centros de enseñanza escolar, ya no solo para el asunto que nos ocupa de la atención del alumnado con discapacidad auditiva, sino por extensión para otros estudiantes con diversas capacidades. Así se desprende de las palabras de Fernando Camacho:

\begin{abstract}
"Considero muy importante contar con el apoyo de un especialista, por ejemplo un logopeda, que pueda informar al docente sobre aspectos particulares del alumno. (...). En el centro donde yo imparto clase los alumnos/as desde muy pequeños trabajan acompañados de un brillante equipo de logopedas que les acompañan durante todas las etapas educativas (de infantil hasta bachillerato o FP). Sin el trabajo de ellas sería muy difícil realizar la labor no solo en música, sino en todas las materias que forman el currículum educativo. (...). Hace seis años se incluyó una actividad específica para sordos en la cual una profesora especialista con el apoyo de una logopeda impartían una hora de clase semanal en la que trabajaban diferentes aspectos musicales como el ritmo, teoría e incluso entonación, cantando y signando canciones conocidas por los alumnos. Desde hace dos años se ha instaurado un proyecto Ilamado Estimusica, en el que se trabaja la estimulación a través de la música en los primeros ciclos" (F. Camacho, entrevista, 25-05-2020).
\end{abstract}

Finalmente, la investigación confirma que el docente tiene una importancia crucial para el desarrollo y éxito de las prácticas inclusivas, tal y como manifiesta Ainscow (2008, p.264), tanto por sus actitudes como por sus creencias. Y es que, "el éxito o el fracaso de todo planteamiento metodológico dependen en gran medida de la persona que lo lleve a cabo, o sea, el docente", afirma Cabrera (2009: 38). 
El Aprendizaje del Violín en Alumnado con Discapacidad Auditiva Luis Sánchez Sánchez

\section{Referencias bibliográficas}

AGUADED, Cinta; IPLAND, Jerónima. Medios audiovisuales y alumnos con necesidades educativas especiales. Comunicar, Huelva, n. 11, p. 212-215, 1998. https://www.redalyc.org/pdf/158/15801133.pdf AGUILAR, Sonia; BARROSO, Julio. La triangulación de datos como estrategia en investigación educativa. Píxel-Bit. Revista de Medios y Educación, Sevilla, n. 47, p. 73-88, 2015. https://www.redalyc.org/ pdf/368/36841180005.pdf

AINSCOW, Mel. Garantizar que cada alumno es importante: la mejora de la equidad dentro de los sistemas. En: GAIRÍN, Joaquín; ANTÚNEZ, Serafín (coord.). Organizaciones educativas al servicio de la sociedad. Madrid: Wolters Kluwer España, 2008, p. 261-282. ARIAS, María Mercedes. La triangulación metodológica: sus principios, alcances y limitaciones. Investigación y educación en enfermería, Medellín, v. 18, n. 1, p. 13-26, 2000. https://www.redalyc.org/ pdf/1052/105218294001.pdf

ARNAIZ, Pilar. La educación inclusiva en el siglo XXI. Avances y desafíos: Lección magistral leída en el acto académico de Santo Tomás de Aquino. Universidad de Murcia: Servicio de Publicaciones, 2019. 47p. BERNAL, José Luis; GAYTÁN, Tatiana. Alumnado con alto rendimiento. Cuadernos de Pedagogía, v. 12, n. 409, p. 52-57, 2011.

BETRIÁN, Ester; GALITÓ, Núria; GARCÍA, Núria; JOVÉ, Glòria; MACARULLA, Marta. La triangulación múltiple como estrategia metodológica. Revista Iberoamericana sobre Calidad, Eficacia y Cambio en Educación (REICE), Madrid, v. 11, n. 4, p. 5-24, 2013. https:// www.redalyc.org/pdf/551/55128238001.pdf

CABERO, Julio; CÓRDOBA, Margarita. Inclusión educativa: inclusión digital. Revista Educación Inclusiva, v. 2 n. 1, p. 61-77, 2009.

CABRERA, Rosell. Métodos activos para la clase de música. Revista digital Ciencia y Didáctica, n. 26, p. 29-38, 2009. 
El Aprendizaje del Violín en Alumnado con Discapacidad Auditiva Luis Sánchez Sánchez

CLAUDIO, Javier. El arte del violín. Madrid: Musicales Mega, 1999. $207 p$.

DARROW, Alice Ann. The role of music in deaf culture: implications for music educators. Journal of Research in Music Education, v. 41, n. 2, p. 93-110, 1993. http://citeseerx.ist.psu.edu/viewdoc/ download?doi=10.1.1.938.5998\&rep=rep1\&type=pdf

DIETZ, Gunther. Multiculturalismo, Interculturalidad y Educación: Una aproximación antropológica. Granada: Universidad de Granada, CIESAS, 2003.

DIETZ, Gunther. Multiculturalism, Interculturality and Diversity in Education: an anthropo- logical approach. Muenster \& Nueva York: Waxmann, 2009.

DIETZ, Gunther. Hacia una etnografía doblemente reflexiva: una propuesta desde la antropología de la interculturalidad. Revista de Antropología Iberoamericana (AIBR), Madrid, v. 6 n. 1, p. 3-26, 2011. https://doi.org/10.11156/aibr.060102e

DIETZ, Gunther. Reflexividad y diálogo en etnografía colaborativa: el acompañamiento etnográfico de una institución educativa "intercultural" mexicana. Revista de Antropología social, Madrid, v. 21, p. 63-91, 2012. https://doi.org/10.5209/rev_RASO.2012.v21.40050 DONOLO, Danilo Silvio. Triangulación: procedimiento incorporado a nuevas metodologías de investigación. Revista Digital Universitaria, México, v. 10 n. 8, 2009. http://www.revista.unam.mx/vol.10/num8/ art53/int53.htm

DURÁN, David; MIQUEL, Ester. Cooperar para enseñar y aprender. Cuadernos de pedagogía, v. 331, p. 73-76, 2003. GALAMIAN, Iván. Interpretación y enseñanza del violín. Madrid: Pirámide, 1998. 192p.

GARCÍA, Francisco Javier; HERRERO, Joaquín (coords.). Manual de atención al alumnado con necesidades específicas de apoyo educativo derivadas de discapacidad auditiva. Sevilla: Junta de Andalucía - Consejería de Educación, 2008. 62p. 
El Aprendizaje del Violín en Alumnado con Discapacidad Auditiva Luis Sánchez Sánchez

HASH, Phillip. Teaching instrumental music to deaf and hard of hearing students. Research \& Issues in Music Education, v. 1 n. 1, art. 5, 2003. https://ir.library.illinoisstate.edu/cgi/viewcontent. cgi?article $=1032 \&$ context $=\mathrm{fpm}$

HIRAGA, Rumi; KAWASHIMA, Mitsuo. Performance visualization for hearing-impaired students. Journal of Systemics, Cybernetics and Informatics, Int'I Institute of Informatics and Cybernetics, v. 3, n. 5, p. 24-32, 2006.

HOPPENOT, Dominique. El violín interior. Madrid: Real Musical, 2000. $200 p$.

IPLAND, Jerónima; PARRA, Diego. La formación de ciegos y discapacitados visuales: visión histórica de un proceso de inclusión. En: BERRUEZO, María Reyes; CONEJERO, Susana (coord.). El largo camino hacia una educación inclusiva: la educación especial y social del siglo XIX a nuestros días: XV Coloquio de Historia de la Educación, Pamplona-Iruñea, 29, 30 de junio y 1 de julio de 2009. Universidad Pública de Navarra, 2009, p. 453-462.

JÁUDENES, Carmen. Retos y responsabilidades de los profesionales de la educación ante las nuevas generaciones de niños sordos. En: JÁUDENES, Carmen (dir.). Manual básico de formación especializada sobre discapacidad auditiva. Madrid: Confederación Española de Familias de Personas Sordas - FIAPAS, 2004, p. 13-17.

JÁUDENES, Carmen. (coord.) Apoyo a la comunicación oral en el ámbito educativo. Orientaciones prácticas para la aplicación de recursos. Madrid: Confederación Española de Familias de Personas Sordas - FIAPAS, 2007. 20p.

LARA, Gloria; MUÑOZ, Práxedes. Cuestionar la práctica investigativa: experiencias colaborativas en dos regiones en México. Empiria:

Revista de metodología de ciencias sociales, Madrid, n. 44, p. 179211, 2019. https://doi.org/10.5944/empiria.44.2019.25357

Ley Orgánica 2/2006, de 3 de mayo, de Educación (BOE №106 del 04-05-2006). https://www.boe.es/boe/dias/2006/05/04/pdfs/A1715817207.pdf 
El Aprendizaje del Violín en Alumnado con Discapacidad Auditiva Luis Sánchez Sánchez

Ley Orgánica 8/2013, de 9 de diciembre, para la mejora de la Calidad Educativa (BOE N²95 del 10-12-2013). https://www.boe.es/ boe/dias/2013/12/10/pdfs/BOE-A-2013-12886.pdf LÓPEZ DE ARENOSA, Encarnación. Apuntes sobre Didáctica Musical. Madrid: Enclave Creativa, 2004. 181p.

MENUHIN, Yehudi. Violín: seis lecciones con Yehudi Menuhin. Madrid: Real Musical, 1987. 144p.

MONFORT, Marc. Consideraciones metodológicas según etapas educativas y áreas curriculares. En: JÁUDENES, Carmen (dir.). Manual básico de formación especializada sobre discapacidad auditiva. Madrid: Confederación Española de Familias de Personas Sordas FIAPAS, 2004, p. 351-359.

MONTOYA, Juan Carlos. Música para sordos. Aproximación a la flauta dulce con el apoyo audiovisual. En: NAVARRO, Juan; GRACIA, M ${ }^{a}$ Dolores; LINEROS, Rocío; SOTO, Francisco Javier (coords.). Claves para una educación diversa. Murcia: Consejería de Educación, Cultura y Universidades, 2014.

MOSTEYRÍN, Javier. Principios de tactoaudición: iniciación a la música para sordos. Burgos: Gran Vía, 2009. 127p.

MUÑOZ, Práxedes. Dilemas de una antropología comprometida: entre autores y experiencias etnográficas. En PEÑA, Beatriz (eds.). Desarrollo Humano. Madrid: Vision Libros, 2012, p. 249-281. MUÑOZ, Práxedes. Proyectos educativos que favorecen una dialógica emancipatoria sobre la ciudadanía y la solidaridad en la formación del profesorado. En: PÉREZ-FUENTES, María del Carmen (ed.). Innovación docente e investigación en ciencias de la educación. Madrid: Dykinson, 2019, p. 1.113-1.124.

MUÑOZ, Práxedes; MATEO, Cecilia; ÁLVAREZ, Ma Mercedes. Perfiles docentes a partir de una etnografía en la escuela. Investigación acción desde el Prácticum. Historia y Comunicación Social, Madrid, v. 19, p. 363-374, 2014. https://doi.org/10.5209/rev_HICS.2014.v19.45139 NANAYAKKARA, Suranga Chandima; WYSE, Lonce; ONG, S. H.; TAYLOR, Elizabeth A. Enhancing musical experience for the hearing-impaired 
El Aprendizaje del Violín en Alumnado con Discapacidad Auditiva Luis Sánchez Sánchez

using visual and haptic displays. Human-Computer Interaction, v. 28, n. 2, p. 115-160, 2013.

$\mathrm{NOCl}$, Adolfo. Revisión histórica de los distintos planteamientos pedagógicos en la educación del sordo. En: JÁUDENES, Carmen (dir.). Manual básico de formación especializada sobre discapacidad auditiva. Madrid: Confederación Española de Familias de Personas Sordas - FIAPAS, 2004, p. 313-321.

OTERO, Liliana Elizabeth. La sordera: una oportunidad para descubrir la música. Revista Española de Discapacidad (REDIS), Madrid, v. 3 n. 2, p. 133-137, 2015. https://www.cedd.net/redis/index.php/redis/article/ view/185/pdf_38

PASCUALI, Giulio; PRÍNCIPE, Remy. El violín: Manual de cultura y didáctica violinística. Buenos Aires: Melos, 2007. 316p.

PEÑALBA, Alicia; MORIYÓN, Carlos; LUQUE, Sonia; CABEZAS, Gonzalo. La metáfora conceptual como recurso pedagógico musical para personas sordas y con discapacidad auditiva. En: Actas del Congreso CNLSE de la Lengua de Signos Española, p. 87-108, 2017.

QUINTERO, Fidela. “Tras la huella de don Quijote": integrarse, participar, ser uno más. Integración, n. 33, p. 26-32, 2000.

Real Decreto 1577/2006, de 22 de diciembre, por el que se fijan los aspectos básicos del currículo de las Enseñanzas Profesionales de Música reguladas por la Ley Orgánica 2/2006, de 3 de mayo, de Educación (BOE Nº18 del 20-01-2007).

RIVERO, Milagros; ZAMORA, Rolando; PADRÓ, Aleida. Estrategia educativa para la formación de deficientes auditivos como profesionales de Cultura Física. Revista Digital, n. 127, 2008. https:// www.efdeportes.com/efd127/formacion-de-deficientes-auditivos-comoprofesionales-de-cultura-fisica.htm

RODRÍGUEZ, Clemente; POZO, Teresa; GUTIÉRREZ, José. La triangulación analítica como recurso para la validación de estudios de encuesta recurrentes e investigaciones de réplica en Educación Superior. Revista Electrónica de Investigación y Evaluación Educativa (Relieve), Valencia, v. 12, n. 2, p. 289-305, 2006. https://doi. org/10.7203/relieve.12.2.4231 
El Aprendizaje del Violín en Alumnado con Discapacidad Auditiva Luis Sánchez Sánchez

SABBATELLA, Patricia. Intervención musical en el alumnado con necesidades educativas especiales: delimitaciones conceptuales desde la pedagogía musical y la musicoterapia. Tavira: Revista de ciencias de la educación, n. 20, p. 123-140, 2004.

SÁNCHEZ, Luis. Educación inclusiva con músicos invidentes: aprendizaje de la viola. Opción: Revista de Ciencias Humanas y Sociales, v. 32, n. 10, p. 734-742, 2016. https://produccioncientificaluz.org/index.php/ opcion/article/view/21846

SÁNCHEZ, Luis. La didáctica del violín en alumnos con discapacidad visual. Compendio de Buenas Prácticas, recursos y estrategias metodológicas para una Educación Inclusiva en las Enseñanzas Elementales y Profesionales de Música. Tesis doctoral. Universidad Católica San Antonio de Murcia, 2017, 481 p. https://repositorio.ucam. edu/handle/10952/2589

SÁNCHEZ, Luis; MUÑOZ, Práxedes. Estrategias metodológicas en el aula de violín para el alumnado con discapacidad visual. En: NAVARRO, Juan; GRACIA, Ma Dolores; LINEROS, Rocío; SOTO, Francisco Javier (coords.). Claves para una educación diversa. Murcia: Consejería de Educación, Cultura y Universidades, 2014a. https://diversidad. murciaeduca.es/publicaciones/claves/dea.html SÁNCHEZ, Luis; MUÑOZ, Práxedes. Atención a la diversidad en el aula de violín. Buenas prácticas a partir de una etnografía reflexiva. En: RAMIRO, Tamara; RAMIRO, $M^{a}$ Teresa (comps.). Avances en Ciencias de la Educación y del Desarrollo, 2014. Granada: Asociación Española de Psicología Conductual (AEPC), 2014b, p. 861-866.

SÁNCHEZ, Luis; MUÑOZ, Práxedes. La enseñanza de orquesta y música de cámara con discapacitados visuales. Estrategias docentes para el aula a partir de una etnografía reflexiva. En: RAMIRO, Tamara; RAMIRO, Ma Teresa (comps.). Avances en Ciencias de la Educación y del Desarrollo, 2015. Granada: Asociación Española de Psicología Conductual (AEPC), 2015, p. 575-579.

SÁNCHEZ, Luis; MUÑOZ, Práxedes. El trabajo de orquesta y grupo de cámara con estudiantes ciegos. En: MUÑOZ, Práxedes; VITÓN, María Jesús (coords). Comunidad, desarrollo y escenarios educativos 
El Aprendizaje del Violín en Alumnado con Discapacidad Auditiva Luis Sánchez Sánchez

emancipatorios. Reflexionando la alteridad sociocultural. Murcia: Compobell, 2018, p. 165-171.

SÁNCHEZ, Luis; MUÑOZ, Práxedes. La formación de alumnado con discapacidad visual en el marco de los conservatorios de música en España. Revista Electrónica Complutense de Investigación en Educación Musical, v. 17, 49-61, 2020. https://revistas.ucm.es/index. php/RECl/article/view/66689

SKLIAR, Carlos. Una mirada sobre los nuevos movimientos pedagógicos en la educación de los sordos. XX Reuniao Anual do ANPED, Associacao Nacional de Pesquisadores em Educacao. 1997. https:// cultura-sorda.org/wp-content/uploads/2015/03/Una-mirada-sobre-losnuevos-movimientos-pedagogicos.pdf

SVARTHOLM, Kristina. ¿Cómo leerles a los sordos? Resumo de uma palestra dada em Buenos Aires, em, v. 8, 2003

TAYLOR, Steve J.; BOGDAN, Robert. Introducción a los métodos cualitativos de investigación. Barcelona: Paidós, 1987. 343p.

TORRES, Santiago; RODRÍGUEZ, José Miguel; SANTANA, Rafael; GONZÁLEZ, Antonia M. Deficiencia auditiva: aspectos psicoevolutivos y educativos. Málaga: Aljibe, 1995. 340p.

TRANCHEFORT, François-René. Guía de la música sinfónica. Madrid: Alianza Editorial, 1989. 1.320p.

VELASCO, Honorio; DíAZ DE RADA, Ángel. La lógica de la investigación etnográfica. 5. ed. Madrid: Trotta, 2006. 304p.

VITóN, María Jesús. Diálogos con Raquel: Praxis pedagógicas y reflexión de saberes para el desarrollo educativo en la diversidad cultural. Madrid: Popular, 2012. 211p.

VLACHOU, Anastasia. Caminos hacia una educación inclusiva. 2. ed. Madrid: La Muralla, 1999. 264p.

WUYTACK, Jos; BOAL, Graça. Audición musical activa con el musicograma. Eufonía, n. 47, p. 43-55, 2009.

YANG, Hui-Jen; LAY, Yun-Long; LIOU, Yi-Chin; TSAO, Wen-Yu.; LIN, Cheng-Kun. Development and evaluation of computer-aided music- 
El Aprendizaje del Violín en Alumnado con Discapacidad Auditiva Luis Sánchez Sánchez

learning system for the hearing impaired. Journal of Computer

Assisted Learning, v. 23, n. 6, p. 466-476, 2007.

\section{Agradecimentos}

Agradecimiento a todas las personas participantes, por compartir sus conocimientos, testimonios y experiencias, y que han permitido incluir en los resultados de esta investigación diversos recursos, estrategias y consejos que han aportado. También a $D^{a}$ Mónica Rodríguez del Centro de Normalización Lingüística de la Lengua de Signos Española (CNLSE) y Da Eva Ruiz de la Confederación Española de Familias de Personas Sordas (FIAPAS), por la facilitación de algunas fuentes bibliográficas. Y en especial a la Dra. Pilar Arnaiz Sánchez por toda su colaboración durante esta investigación.

\section{Publisher}

Universidade Federal de Goiás. Escola de Música e Artes Cênicas. Programa de Pós-graduação em Música. Publicação no Portal de Periódicos UFG.

As ideias expressadas neste artigo são de responsabilidade de seus autores, não representando, necessariamente, a opinião dos editores ou da universidade. 